\title{
Acumulação de capital, poupança externa e desempenho macroeconômico dos países emergentes ${ }^{1}$
}

\author{
Marcos Aurélio Andrade Rocha ${ }^{2}$ \\ José Luis Oreiro ${ }^{3}$
}

\section{Resumo}

O presente artigo tem por objetivo apresentar um modelo dinâmico não linear para avaliar a relação entre poupança externa e endividamento externo "excessivo" em países emergentes, resultante da existência de grandes déficits em conta corrente. Para tanto, iremos apresentar um modelo dinâmico no qual (i) um aumento do endividamento externo como proporção do PIB gera um aumento menos do que proporcional na taxa de investimento, uma vez que uma parte do financiamento externo é usada para a aquisição de ativos não reprodutíveis (imóveis e ações); e (ii) o prêmio de risco país é endógeno, crescendo de forma proporcional com o endividamento externo como proporção do PIB. Nesse arcabouço teórico demonstra-se a existência de equilíbrios múltiplos. Mais especificamente, no plano teórico, o artigo tem por objetivo isolar os mecanismos econômicos pelos quais a poupança externa, tendo por veículo o endividamento externo, tem como resultado possível um equilíbrio de baixa lucratividade e uma baixa taxa de retorno sobre o capital, configurando assim uma situação de estagnação econômica. Para testar os efeitos da poupança externa e endividamento nos termos do modelo teórico, é construído um modelo de crescimento com painel dinâmico que avalia se a poupança externa efetivamente tem impacto negativo sobre os resultados em termos de produto per capita dos emergentes.

Palavras-chave: Poupança externa; Acumulação de capital; Flutuações econômicas; Endividamento externo; Competitividade externa.

\section{Abstract \\ Capital accumulation, foreign savings and macroeconomic performance of emerging countries}

This paper aims to present a non-linear dynamic model to evaluate the relationship between external savings and "excessive" external borrowings in emerging countries, resulted from large current account deficits. For this intent, it is present a post-Keynesian model in which (i) an increase in the external borrowings as gross domestic product share generates an less than proportional increase in the investment rate, since part of external financing is used to acquire non-reproducible assets (buildings and equities), (ii) the country-risk premium of a country is endogenous, increasing proportionally to the external borrowing as GDP share. Specifically, on theoretical dimension, the paper intends to isolate the economic mechanisms by which the external savings, through external

(1) Trabalho recebido em outubro de 2008 e aprovado em novembro de 2009. O suporte financeiro do CNPq é reconhecido.

(2) Doutorando em Economia pela Escola de Economia de São Paulo da Fundação Getúlio Vargas (EESP/FGV-SP) e Professor Assistente da Pontifícia Universidade Católica (PUC), São Paulo, SP, Brasil. E-mail: marcosrocha@gvmail.br.

(3) Professor Adjunto do Departamento de Economia da Universidade de Brasília (UnB)/Pesquisador Nível I do Conselho Nacional de Desenvolvimento Científico e Tecnológico (CNPq) e Diretor da Associação Keynesiana Brasileira. E-mail: joreiro@unb.br. Página pessoal: www.joseluisoreiro.ecn.br.

Economia e Sociedade, Campinas, v. 20, n. 1 (41), p. 33-52, abr. 2011 
borrowings as vehicle, has as low profit rate equilibrium and low rate of return to capital, and hence macroeconomic stagnation. To test the effects of external savings and borrowing in the terms of the formal model, it is estimated a dynamic panel which evaluates if external savings has an effective negative impact over income per capita path of emerging countries.

Keywords: Foreign savings; Capital accumulation; Business-cycles; External debt; External competitiveness.

JEL F3, F4, O2.

\section{Introdução}

Os defensores da conversibilidade da conta de capitais argumentam que um dos benefícios da abertura aos fluxos de capital para os países em desenvolvimento é o maior acesso aos mercados internacionais de capitais e, portanto, a um fluxo maior de poupança externa para esses países. Dado que quanto maior for a taxa de poupança (interna + externa) maior será o nível de renda per capita da economia no longo prazo, de acordo com o modelo neoclássico de crescimento Solow-Swan, segue-se que os países em desenvolvimento deveriam liberalizar as suas contas de capitais de forma a estimular o aumento do nível de renda per capita, reduzindo assim a sua distância com respeito ao nível de renda per capita dos países desenvolvidos.

Essa visão pró-liberalização da conta de capitais se fundamenta, portanto, na hipótese de que o crescimento econômico pode ser estimulado ou induzido pela poupança externa. Como a poupança externa é a contrapartida contábil dos déficits em transações correntes, segue-se dessa linha de raciocínio que o crescimento dos países em desenvolvimento estaria associado a grandes desequilíbrios na conta de transações correntes do balanço de pagamentos.

Uma das principais linhas de argumentação contra a tese de que a poupança externa é necessária para o crescimento dos países em desenvolvimento foi elaborada recentemente por Bresser e Nakano (2003). Para esses autores, o financiamento do crescimento via "poupança externa" tende a gerar uma redução da taxa de crescimento de longo prazo das economias dos países em desenvolvimento devido ao aumento explosivo do endividamento externo que é gerado por essa estratégia de crescimento. Com efeito, esse aumento do grau de endividamento externo torna as economias desses países suscetíveis a crises do balanço de pagamentos, cuja solução exige grandes desvalorizações da taxa nominal e real de câmbio, as quais geram um aumento das taxas de inflação e induzem a adoção de políticas monetária e fiscal restritivas com o intuito de se obter o controle dos índices inflacionários e a geração de grandes superávits comerciais por intermédio da redução da absorção doméstica. Essas políticas de contenção de demanda têm como efeito a elevação da taxa real de juros, a redução do nível de atividade econômica e do investimento em ampliação da capacidade produtiva. 
Com efeito, a Figura 1 apresenta para alguns países de renda média um scatter-plot com a conta corrente como proporção do Produto Interno Bruto (PIB) no eixo vertical e as taxas de crescimento do PIB no eixo horizontal. Visualmente, parece haver relação positiva entre as séries. Essa relação aparente pode motivar uma investigação mais profunda da relação entre poupança estrangeira e produto para países emergentes. ${ }^{4}$

Inspirado nessas considerações, o presente artigo tem por objetivo fazer uma avaliação da hipótese de que o ingresso de poupança externa nos países emergentes, na medida em que acarretam endividamento externo excessivo ${ }^{5}$, pode ter um impacto negativo sobre a performance macroeconômica dos países em desenvolvimento. Mais especificamente, no plano teórico, o artigo tem por objetivo isolar os mecanismos econômicos pelos quais a poupança externa, tendo por veículo o endividamento externo, tem como resultado possível um equilíbrio de baixa lucratividade e uma baixa taxa de retorno sobre o capital, configurando assim uma situação de estagnação econômica.

Figura 1

Relação entre a conta corrente/PIB e taxas de crescimento para países selecionados - 1990

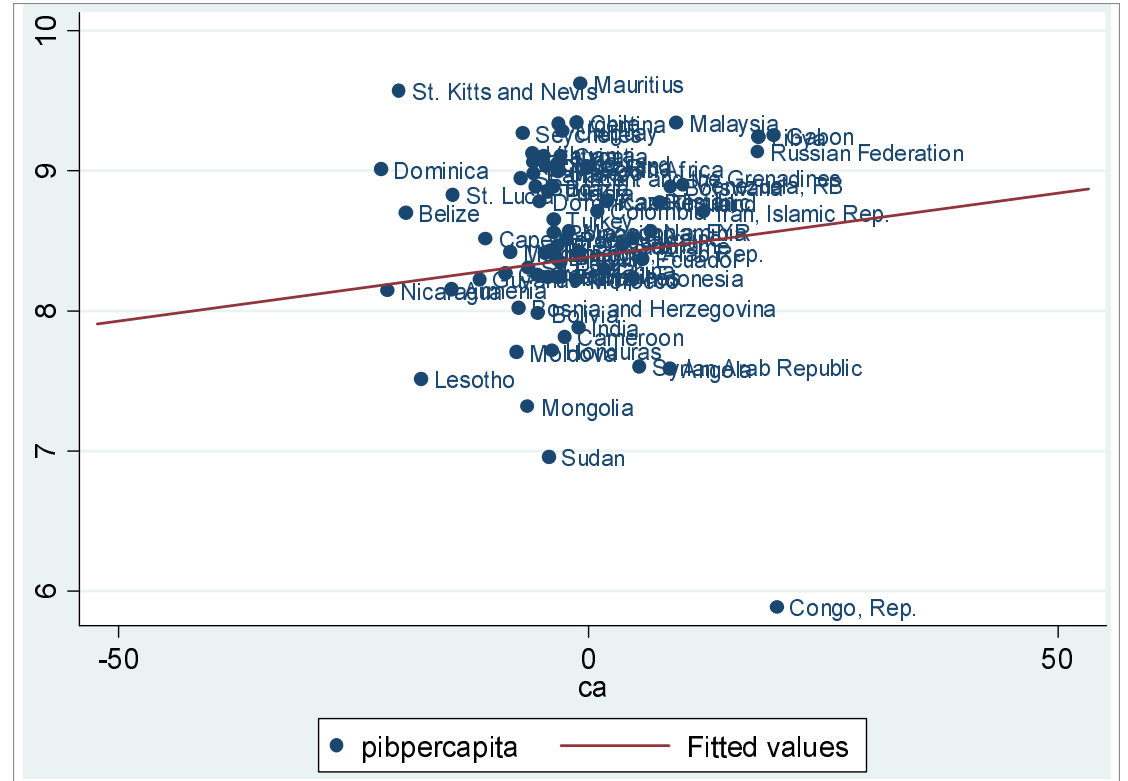

Nota: Exibe correlações não condicionais para ilustrar as relações que, controladas as causalidades, são exploradas na seção econométrica do trabalho.

Fonte: World Development Indicators (2008).

(4) Uma vez que a os resultados negativos na conta corrente configuram a entrada de poupança externa, a relação positiva entre conta corrente e crescimento do PIB tem como contrapartida a relação negativa entre o influxo de poupança estrangeira e o crescimento do PIB.

(5) O endividamento excessivo, aqui, se trata daquele formalizado nos termos do modelo teórico explorado neste trabalho. 
Para isso, o presente artigo desenvolve um modelo pós-keynesiano de crescimento para uma economia aberta, no qual (i) o investimento em capital fixo é uma função não linear do endividamento externo como proporção do produto; e (ii) a taxa de juros doméstica é uma função crescente do endividamento externo devido ao efeito que um maior endividamento (como proporção do PIB) tem sobre o prêmio de risco país. A implicação central do modelo é de que a influência da poupança externa, ao acumular um endividamento externo além de certo limite, tem um impacto negativo sobre o nível de atividade econômica. Fica, portanto, evidenciado um mecanismo de transmissão potencial de restrições de longo prazo gerado pelo influxo de poupança externa sobre o crescimento.

Para testar a hipótese levantada pelo modelo teórico, um modelo empírico de crescimento busca testar se a poupança externa efetivamente tem impacto negativo nos resultados em termos de produto per capita dos países emergentes.

Dado isso, o presente artigo está estruturado em quatro seções, incluindo a presente introdução. Na seção 1 iremos apresentar a estrutura básica do modelo de crescimento. Na seção 2 são apresentadas as bases de dados utilizadas e os testes empíricos. Por fim, as conclusões sumarizadas.

\section{Acumulação de capital e endividamento externo}

Nesta seção iremos apresentar um modelo de crescimento puxado pela demanda agregada para uma pequena economia aberta que opera sob um regime de câmbio fixo e uma conta de capital plenamente conversível. O investimento e as exportações supostamente são os componentes autônomos da demanda agregada, o que está em forte contraste com os modelos padrão de crescimento com restrição do balanço de pagamentos $^{6}$ nos quais as exportações são consideradas a única fonte de demanda autônoma para a economia em geral (Thirwall, 2002, p. 55). ${ }^{7}$ Para fins de simplicidade do modelo, iremos supor que os gastos do governo e os impostos são fixados em zero.

\subsection{Os blocos fundamentais do modelo}

Consideremos uma economia na qual as empresas produzem um bem homogêneo utilizando força de trabalho e matérias-primas importadas. A

(6) Sobre os modelos de crescimento com restrição de balanço de pagamentos, ver McCombie e Thirwall (1994)

(7) Segundo Kaldor (1988), no longo prazo as fontes de demanda autônoma para a economia como um todo são dadas apenas pelos gastos do governo e pelas exportações, uma vez que o investimento é suposto ser determinado pelo acelerador harrodiano, de forma que os gastos de investimento são tratados como totalmente endógenos no longo prazo. De acordo com o nosso entendimento a respeito da teoria keynesiana do investimento, contudo, o investimento possui um componente puramente autônomo, mesmo no longo prazo, devido à influência exercida pelo animal spirits sobre as decisões de investimento. Isso significa que é inaceitável tanto no âmbito teórico como no empírico tratar o investimento como uma variável puramente endógena, como é suposto pelos modelos de crescimento com restrição de balanço de pagamentos. 
tecnologia de produção dessa economia é do tipo Leontieff, de tal forma que os coeficientes técnicos de trabalho e de matérias-primas - ou seja, as quantidades de trabalho e de matérias-primas necessárias para a produção de uma unidade de produto - são independentes do nível de produção das firmas. Por simplicidade, iremos considerar uma economia desprovida de progresso tecnológico de forma que a produtividade do trabalho - definida como a recíproca do requisito unitário de mão de obra - é constante ao longo do tempo.

Tal como é suposto na maior parte dos modelos de crescimento de inspiração pós-keynesiana - por exemplo, Lima (1999) - iremos supor que as empresas dessa economia possuem poder de mercado e fixam os preços de seus produtos com base num mark-up constante sobre os custos variáveis de produção. Sendo assim, a equação de preço dessa economia é dada por (cf. Taylor, 1989, p. 21):

$$
p=(1+\tau)\left[w b+e p_{0}^{*} a_{0}\right]
$$

onde: $p$ é o nível de preços doméstico, $w$ é a taxa de salário nominal, $p$ é o nível de preços internacional, $e$ é a taxa nominal de câmbio, $b$ é o requisito unitário de mão de obra, $a_{0}$ é o requisito unitário de matérias-primas importadas e $\tau$ é a taxa de mark-up.

Seja $r$ a taxa de lucro e $u$ o grau de utilização da capacidade produtiva. Pode-se demonstrar que a taxa de lucro é dada por:

$$
r=\frac{\tau}{1+\tau} u
$$

Assim, pode-se observar que a lucratividade é uma função crescente do mark-up ${ }^{8}$ e do grau de utilização da capacidade produtiva.

O mercado de bens está em equilíbrio quando a oferta agregada for igual ao nível de produção das firmas:

$$
p C+p I+p E=p X
$$

onde: $p C$ é o valor nominal dos gastos de consumo, $p I$ é o valor nominal dos gastos de investimento, $p E$ é o valor nominal das exportações líquidas e $p X$ é o valor nominal do nível de produção.

Adicionalmente, supõe-se a existência de duas classes sociais (capitalistas e trabalhadores) que se diferenciam entre si com base na classe de rendimentos (lucros e salários) e com base na propensão a consumir da renda disponível.

(8) O mark-up é tido como constante por depender de variáveis estruturais como: i) grau de monopólio; ii) o nível das barreiras à entrada de novos competidores na indústria; e iii) o grau de substituibilidade entre os produtos das firmas de uma mesma indústria.

Economia e Sociedade, Campinas, v. 20, n. 1 (41), p. 33-52, abr. 2011. 
Assume-se que os trabalhadores "consomem tudo o que ganham" de forma que a sua propensão a consumir é igual a um. ${ }^{9}$ Por outro lado, os capitalistas consomem uma fração $c_{p}$ dos seus rendimentos (os quais são constituídos unicamente de lucros), poupando uma fração $s_{p}=\left(1-c_{p}\right)$ da sua renda. Sendo assim, o valor nominal dos gastos de consumo é dado por:

$$
p C=w b X+\left(1-s_{c}\right) r p K
$$

Substituindo (4) em (3) tem-se que:

$$
\frac{I}{K}+\frac{E}{K}-s_{c} r-q a_{0} m r=0
$$

onde $q=\frac{e p^{*}}{p}$ é a taxa real de câmbio e $m=\frac{\tau}{1+\tau}$ é a participação dos lucros na renda.

Nesse modelo, a taxa de crescimento do estoque de capital $(\mathrm{I} / \mathrm{K}=\mathrm{g})$ é uma função positiva de um componente autônomo $\left(\alpha_{0}\right),{ }^{10}$ da diferença entre a taxa de lucro e taxa de juros $\left(\alpha_{1}[r-i]\right)$ e por fim de um componente que depende do endividamento externo como proporção do estoque de capital $\left(\alpha_{2} z^{\psi}\right){ }^{11}$ Iremos assumir que um aumento do endividamento externo como proporção do estoque de capital irá resultar num aumento menos do que proporcional do I/K, ou seja, $\psi<1.12$

$$
\frac{I}{K}=\alpha_{0}+\alpha_{1}[r-i]+\alpha_{2} z^{\psi} \quad 0<\psi<1
$$

Na equação (6) estamos fazendo a hipótese keynesiana convencional de que o investimento é positivamente influenciado pela diferença entre a taxa corrente de lucro - a qual é uma proxy da taxa esperada de retorno dos novos projetos de investimento (cf. Possas, 1987) - e a taxa nominal de juros. ${ }^{13}$ O elemento novo na função investimento é a dívida externa como proporção do estoque de capital. A sua incorporação na função investimento tem por objetivo apresentar as restrições de financiamento externo à decisão de investimento em

(9) Ou seja, a sua propensão a poupar é igual a zero.

(10) O qual reflete, por exemplo, o "animal spirits" dos capitalistas. A esse respeito ver Keynes (1936, cap. 12) e Marglin (1984, p. 81-95).

(11) $\mathrm{z}=\mathrm{D} / \mathrm{K}$ é o endividamento externo como proporção do estoque de capital.

(12) Isso porque estamos supondo, em conformidade com a experiência das economias emergentes, que uma parte dos capitais externos é utilizada para a aquisição de ativos não reproduzíveis como, por exemplo, terras.

(13) Por simplicidade, estamos supondo que a taxa esperada de inflação é igual a zero. 
capital fixo. ${ }^{14}$ Com efeito, tal como salientado por Bresser e Nakano (2003, p. 14), o investimento é limitado, numa economia aberta, pela capacidade de importar bens de capital. Nesse contexto, o endividamento externo pode atuar no sentido de relaxar a restrição de divisas à compra de bens de capital no exterior; contribuindo dessa forma para aumentar o investimento realizado pelos empresários.

Pode-se observar na equação (6) que o efeito do endividamento externo sobre a taxa de investimento é não linear. Mais especificamente, supõe-se que um aumento do endividamento externo como proporção do estoque de capital irá gerar um acréscimo menos do que proporcional na taxa de investimento. Essa hipótese pode ser justificada com base na ideia de que o endividamento externo não é plenamente destinado ao financiamento do investimento em capital fixo, mas destina-se, em parte, ao financiamento da aquisição de ativos financeiros como, por exemplo, ações e títulos do governo. Sendo assim, o aumento do endividamento externo não irá resultar num acréscimo proporcional da taxa de investimento.

As exportações líquidas dependem de um componente autônomo $\left(\varepsilon_{0}\right)^{15} \mathrm{e}$ negativamente do nível de utilização da capacidade produtiva, pois supõe-se que o aumento da atividade econômica implica um aumento das importações, o que reduz o saldo da balança comercial. Assim, pode-se escrever a função da seguinte forma $^{16}$ :

$$
\frac{E}{K}=\varepsilon_{0}-\varepsilon_{1} u
$$

Considera-se que o prêmio risco é endógeno, ${ }^{17}$ sendo dado pela seguinte equação:

$$
\rho=\rho_{0}+\rho_{1} \cdot z
$$

onde: $\rho_{0}>0 ;$ e $\rho_{1}>0$.

(14) Estamos introduzindo a restrição externa ao crescimento de uma forma diferente daquela considerada pelos modelos de crescimento com restrição de balanço de pagamentos, como, por exemplo, o desenvolvido por Moreno-Brid (1998). Com efeito, Moreno-Brid analisou o impacto dos fluxos de capital sobre a restrição de balanço de pagamentos, mas deixou em aberto a questão referente aos determinantes da taxa efetiva de crescimento do produto real. Isso significa que, em equilíbrio, é possível que a taxa de crescimento efetiva do produto real - em larga medida, determinada pela taxa desejada de acumulação de capital - seja inferior à taxa de crescimento compatível com o equilíbrio do balanço de pagamentos. Nesse caso, a acumulação de capital e o crescimento econômico seriam independentes dos fluxos de capital, o que parece estar em contradição com a evidência empírica disponível para os países emergentes.

(15) O qual depende, entre outras variáveis, da taxa real de câmbio. Como estamos supondo a existência de um regime de câmbio fixo bem como rigidez de preços tanto no âmbito doméstico como no internacional, segue-se que a taxa real de câmbio pode ser tratada como constante e, dessa forma, incorporada ao componente autônomo da função de exportações líquidas.

(16) Nesse modelo, o efeito do câmbio é fixo e está sendo captado no termo $\varepsilon_{0}$.

(17) A respeito da endogeneidade do prêmio de risco nos países emergentes, com referência particular ao Brasil, ver Holland e Vieira (2003). A hipótese de endogeneidade do prêmio de risco acha-se também explicitada em Oreiro $(2002,2004)$. 
A equação (8) mostra que o prêmio risco é uma função crescente da dívida externa como proporção do estoque de capital. A ideia é que quanto maior for o endividamento externo maior será o volume de compromissos externos do país na forma de juros e amortização sobre o principal, aumentando assim o risco de default (Oreiro, 2004).

Para fechar o modelo, temos ainda que especificar os determinantes da taxa nominal de juros. Com esse objetivo em mente, iremos supor que a economia em consideração exibe conversibilidade plena da sua conta de capitais - ou seja, existe mobilidade perfeita de capitais no sentido usado no modelo MundellFleming - e que prevalece o regime de câmbio fixo. Nesse contexto, a taxa nominal de juros é determinada com base na paridade descoberta da taxa de juros, sendo dada pela seguinte equação:

$$
i=i^{*}+\rho
$$

Substituindo (8) e (9) em (6), obtemos uma equação que determina o investimento como proporção do estoque de capital como função do endividamento externo e da lucratividade:

$$
\frac{I}{K}=g=\alpha_{0}+\alpha_{1}\left[r-\left(i^{*}+\rho_{0}+\rho_{1} z\right)\right]+\alpha_{2} z^{\psi}
$$

Com base na equação (10), pode-se observar que a taxa de crescimento do estoque de capital ( $I / K=g=$ taxa de crescimento do produto real) depende da lucratividade e do endividamento externo.

Assim, a relação entre a taxa de crescimento do estoque de capital e o endividamento externo pode ser visualizada a partir da Figura 2 abaixo ${ }^{18}$ :

Figura 2

Taxa de crescimento como função do endividamento externo

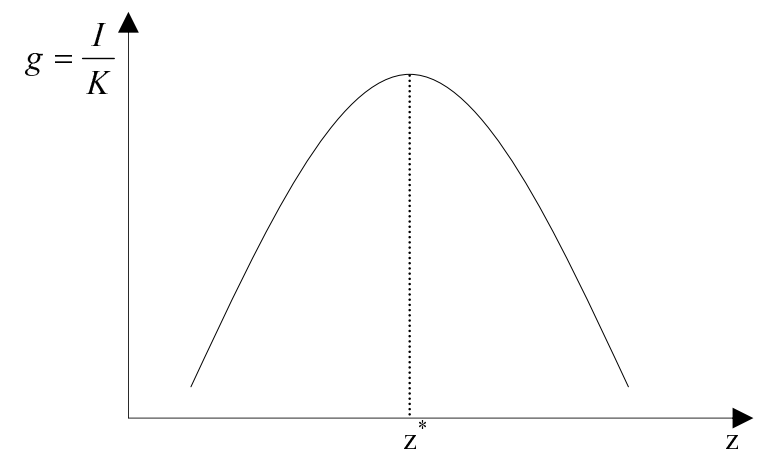

(18) Admitindo que $(0<\mathrm{k}<1)$, percebe-se os controles atuarão no sentido de deslocar para cima a curva representada na Figura 1. As linhas tracejadas representam as curvas sem o impacto dos controles de capitais. 
Diferenciando (10) com respeito a $z$, obtém-se:

$$
\frac{\partial(I / K)}{\partial z}=\psi \alpha_{2} z^{\psi-1}-(1-k) \alpha_{1} \rho_{1}
$$

Colocando-se u em evidência na equação (2) e substituindo a resultante em (7) obtém-se:

$$
\frac{E}{K}=\varepsilon_{0}-\varepsilon_{1} \frac{(1+\tau)}{\tau} r
$$

Substituindo (10) e (12) em (5), obtém-se o lócus $\dot{r}=0$ :

$$
0=\left[\left(\gamma+\alpha_{1} r+\alpha_{2} z^{\psi}-\alpha_{1}\left(i^{*}+\rho_{0}+\rho_{1} z\right)-\varepsilon_{1} m^{-1} r-s_{c} r-q a_{0} m r\right]\right.
$$

onde $\gamma \equiv \alpha_{0}+\varepsilon_{0}$.

A equação (13) apresenta a taxa corrente de lucro para o qual a demanda agregada é igual à oferta. Trata-se do valor de equilíbrio de curto prazo da taxa de lucro.

Colocando $r$ na equação (13) em evidência e diferenciando com respeito a $r$ e $z$, obtemos a seguinte expressão:

$$
\left(\frac{\partial r}{\partial z}\right)_{r=0}=\left(\frac{m\left(\psi \alpha_{2} z^{\psi-1}-\alpha_{1} \rho_{1}\right)}{\varepsilon_{1}+s_{c} m+q a_{0} m^{2}-\alpha_{1} m}\right)
$$

O sinal de $\left(\frac{\partial r}{\partial z}\right)_{r=0}$ dependerá de $\psi \alpha_{2} z^{\psi-1}-\alpha_{1} \rho_{1}$, que varia com $z$. Assim, à medida que $z$ aumenta, o sinal de $\frac{\partial r}{\partial z}$ passará de positivo para negativo, caracterizando uma relação não linear entre a lucratividade e o endividamento externo.

A relação entre endividamento externo e lucratividade pode ser visualizada por intermédio da Figura 3:

\section{Figura 3}

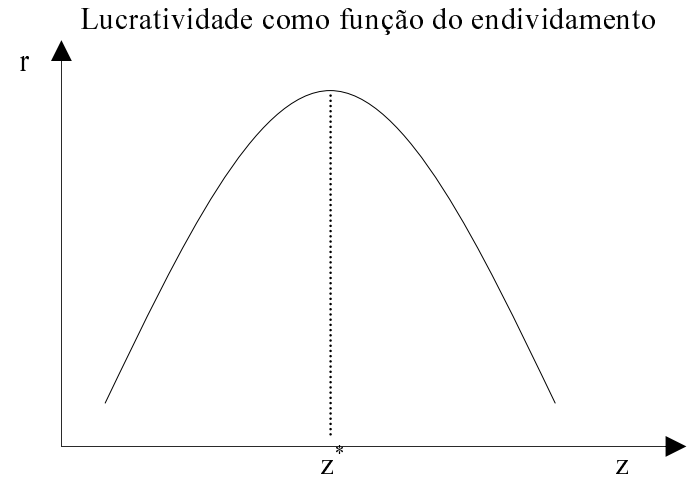

Economia e Sociedade, Campinas, v. 20, n. 1 (41), p. 33-52, abr. 2011. 


\subsection{Endividamento externo e equilíbrios múltiplos: a dinâmica do modelo no longo prazo}

Para analisar a dinâmica de longo prazo dessa economia, parte-se da equação da dinâmica do endividamento descrita por Simonsen e Cisne (1995):

$$
\dot{D}=i^{e} D-H
$$

onde: $D$ é o estoque total de endividamento externo, $H$ é a transferência líquida de recursos para o exterior e $i^{e}$ é a taxa de juros da dívida externa. A taxa de juros da dívida externa é determinada pela equação:

$$
i^{e}=i^{*}+\rho_{0}+\rho_{1} z
$$

Diferenciando $z$ com respeito ao tempo, obtemos a seguinte expressão:

$$
\dot{z}=\frac{\dot{D}}{K}-\frac{\dot{K}}{K} \frac{D}{K}
$$

onde $\frac{\dot{K}}{K}$ é a taxa de crescimento do estoque de capital $(\mathrm{g}) .{ }^{19}$

Substituindo (15) e (16) em (17), obtemos a seguinte expressão:

$$
\dot{z}=\left(i^{e}-g\right) z-\frac{H}{K}
$$

A transferência líquida de recursos para o exterior nada mais é, na economia em consideração, do que o valor das exportações líquidas $\frac{H}{K}=\frac{E}{K} \cdot{ }^{20}$ Substituindo (10) e (12) em (18), tem-se a expressão final para a dinâmica da dívida externa dada por:

$$
\dot{z}=\left(i^{*}+\rho_{0}+\rho_{1} z-\alpha_{0}-\alpha_{1}\left[r-\left(i^{*}+\rho_{0}+\rho_{1} z\right)\right]-\alpha_{2} z^{\psi}\right) z-\varepsilon_{0}+\varepsilon_{1} m^{-1} r
$$

$\mathrm{Na}$ equação (19) estamos considerando que a taxa real de câmbio permanece fixa no longo prazo. A ideia subjacente a essa hipótese é que o governo adota uma política de peg da taxa real de câmbio, fixando a taxa de desvalorização do câmbio nominal num patamar igual à diferença entre a taxa de inflação doméstica e a taxa de inflação internacional de forma a manter a taxa real de câmbio no nível desejado no longo prazo. Dessa forma, o câmbio real é suposto uma variável de política econômica, cuja determinação, no entanto, envolve um trade-off entre competitividade externa e salário real. Com efeito, quanto mais

(19) Supondo que a relação capital-produto é constante ao longo do tempo, segue-se que a taxa de crescimento do produto real será igual à taxa de crescimento do estoque de capital.

(20) Estamos supondo que o saldo da balança de serviços não fatores é igual a zero. 
desvalorizada for a taxa real de câmbio, maior será o componente autônomo das exportações líquidas e, portanto, menor será a acumulação de endividamento externo. No entanto, um câmbio mais desvalorizado implica, dada a taxa de markup, um salário real menor para os trabalhadores, o que pode ter um impacto desfavorável em termos políticos para o governo, especialmente em regimes democráticos. Sendo assim, governos de países diferentes poderão escolher níveis diferentes de taxa real de câmbio, a depender das peculiaridades do cenário político interno, o que irá gerar níveis diferentes de competitividade-preço para as diversas economias do mundo.

Colocando $r$ na equação (19) em evidência e diferenciando com respeito a $r$ e $z$, tem-se o lócus $\dot{z}=0$ :

$0\left(\frac{\partial r}{\partial z} \mid \dot{z}=0\right)=\left(\frac{\Phi_{0}+\Phi_{1} z-\alpha_{2} \psi z^{\psi-1}-\alpha_{2} z^{\psi /}}{\varepsilon_{1}-z m \alpha_{1}}\right)+\alpha_{1} m^{2}\left(\frac{\varepsilon_{0}-i_{p} z-i_{p} \alpha_{1} z+\left(i_{p}\right) \alpha_{1} z+\alpha_{2} z^{\psi+1}}{\left(\varepsilon_{1}-z m \alpha_{1}\right)^{2}}\right)$

onde:

$$
\begin{gathered}
\Phi_{0}=i^{*}+\rho_{0}-\alpha_{0}-\alpha_{1} r+\alpha i^{*}+\alpha_{1} \rho_{0}-\alpha_{1} i^{*}-\rho_{0} \alpha_{1}>0 ; \\
\Phi_{1}=\left(2 \rho_{1}+2 \alpha_{1} \rho_{1}-2 \alpha_{1} \rho_{1}\right)>0 \\
i_{p}=i^{*}+\rho_{0}+\rho_{1} z>0 .
\end{gathered}
$$

A equação (20) mostra que o efeito de um aumento do endividamento sobre a lucratividade depende do próprio nível de endividamento. Supondo que $\varepsilon_{1}-z m \alpha_{1}>0$, o sinal de $\left(\frac{\partial r}{\partial z}\right)_{z=0}$ dependerá do endividamento externo. Para um $z$ baixo, a inclinação é positiva, enquanto para valores de $z$ elevados, a inclinação é negativa. Uma das possíveis representações gráficas da dinâmica da dívida externa está descrita na Figura 4, abaixo:

Figura 4

Lócus de equilíbrio da dívida externa

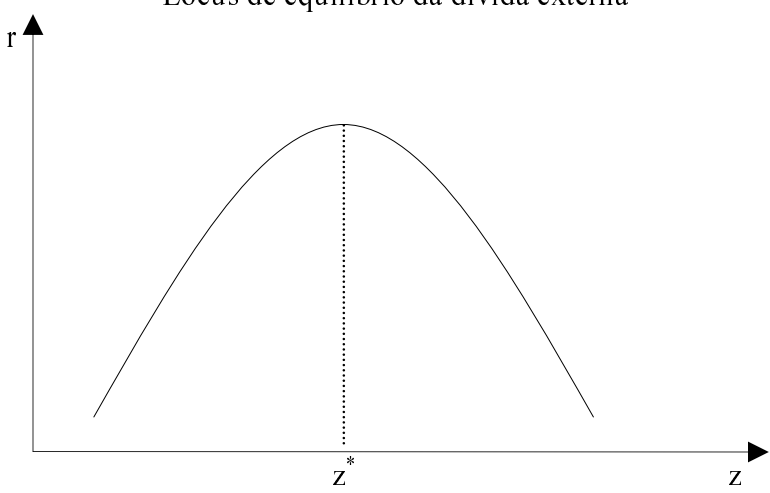

Economia e Sociedade, Campinas, v. 20, n. 1 (41), p. 33-52, abr. 2011. 
Em steady-state tem-se que a taxa de lucro e o endividamento externo são constantes ao longo do tempo. Isso nos permite definir o lócus $\dot{r}=0$ e o lócus $\dot{z}=0$, cujas inclinações são dadas respectivamente pelas equações (14) e (20).

Dessa forma, como base nas equações (14) e (20), pode-se facilmente mostrar que uma das configurações possíveis de equilíbrio de longo prazo da economia em consideração corresponderia à visualizada por intermédio da Figura 5.

Figura 5

Equilíbrios múltiplos

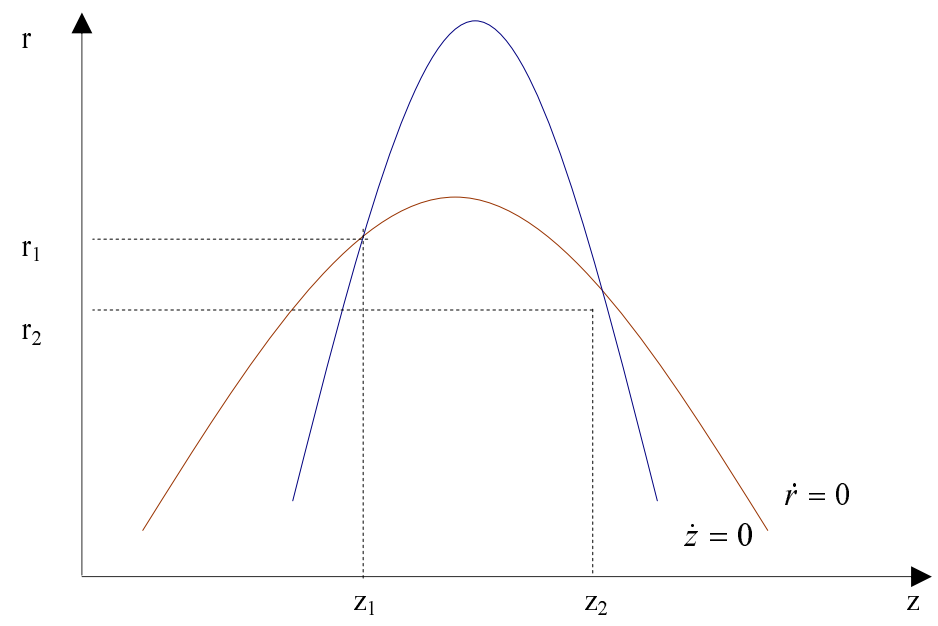

Anteriormente foi demonstrado que o lócus que descreve as combinações de $r$ e $z$ para as quais o mercado de bens se encontra em equilíbrio. As curvas têm o formato aproximado de uma parábola com concavidade voltada para baixo.

Na Figura 5 percebe-se a existência de duas posições de equilíbrio de longo prazo. A primeira caracterizada por uma lucratividade elevada $\left(r_{1}\right)$ e um baixo nível de endividamento externo $\left(\mathrm{z}_{1}\right)$ - a qual chamaremos de equilíbrio com baixo endividamento - e a segunda caracterizada por uma lucratividade baixa $\left(\mathrm{r}_{2}\right)$ e um alto nível de endividamento externo $\left(\mathrm{z}_{2}\right)$ - a qual chamaremos de equilíbrio com alto endividamento. Daqui se segue que o influxo de capital externo, na medida em que tende a levar a um "endividamento externo excessivo", tem como resultado possível um equilíbrio de baixa lucratividade e uma baixa taxa de retorno sobre o capital, configurando assim uma situação de estagnação econômica. Isso porque no modelo aqui proposto, um equilíbrio no qual a taxa de lucro é baixa configura uma situação na qual o grau de utilização da capacidade produtiva também é baixo, uma vez que a participação dos lucros na renda é suposta como constante em função da constância da taxa de mark-up. Como a taxa 
de acumulação de capital é uma função positiva do grau de utilização da capacidade produtiva e negativa - após o limite crítico de endividamento $\mathrm{z}^{*}$ - do endividamento externo como proporção do estoque de capital, segue-se que no equilíbrio com alto endividamento a taxa de crescimento do estoque de capital será menor do que a que prevaleceria caso a economia operasse com um nível mais baixo de endividamento.

\section{Evidências empíricas}

Vimos no modelo teórico que o ingresso de capital estrangeiro pode ter, através do endividamento externo, consequências nocivas sobre o desempenho de crescimento dos países.

O objetivo da presente seção é testar se a poupança externa exerce efeitos sobre o desempenho macroeconômico de países emergentes, a partir da análise de um painel de dados de 73 países de renda média ${ }^{21}$ - segundo a classificação do Banco Mundial, listada no Apêndice I - para o período de 1980 a 2000. São considerados os países low-middle income e high-middle income, de acordo com a classificação por renda feita pelo Banco Mundial. Os dados foram obtidos no World Penn Tables de Heston, Summers e Atina (2006) e das séries do World Development Indicators, do Banco Mundial. No Apêndice I é feita a descrição das variáveis utilizadas nos experimentos empíricos.

\subsection{Testes de raiz unitária}

É bem sabido que um dos grandes desafios para a estimação de modelos macroeconômicos é a existência de raízes unitárias e regressões espúrias [Jones (1995) e Easterly (2001)]. Sabe-se que, para pequenas amostras, os testes de raiz unitária tradicionais têm pequeno poder contra hipóteses alternativas de quase estacionariedade. A análise de painel de dados reduz o problema do pequeno poder dos testes de raiz unitária padrão aumentando o número de observações. Para a análise das variáveis utilizadas no experimento empírico deste trabalho, são reportados os resultados de três testes para raiz unitária em painel: o teste de Levin, Li e Chun, o teste ADF de Dickey e Fuller e o Phillips-Perron. Todos eles são baseados em algum tipo de regressão Dickey Fuller:

$$
\Delta y_{i t}=\alpha_{i}+\rho_{i} y_{i t-1}+\varepsilon_{i t},
$$

onde $i=1, \ldots, N$ é o país, $t=1, \ldots, T$ e $\varepsilon_{i t}$ é iid $\left(0, \sigma_{i}^{2}\right)$.

(21) São eles: África do Sul, Albânia, Argentina, Algéria, Angola, Armênia, Bulgária, Belize, Brasil, Botsuana, Chile, China, Camarões, Congo, Colômbia, Cabo Verde, Costa Rica, Cuba, Djibouti, Dominica, República Dominicana, Equador, Honduras, Croácia, Indonésia, Índia, Irã, Iraque, Jamaica, Kazaquistão, Kiribati, São Kitts, Líbano, Líbia, Santa Lúcia, Sri Lanka, Lesoto, Lituânia, Latvia, Marrocos, Ilhas Maldivas, México, Macedônia, Mongólia, Palau, Polônia, Paraguai, Romênia, Rússia, Sudão, El Salvador, Sérvia, Suriname, Síria, Turcomenistão, Tonga, Turquia, Ucrânia, Uruguai, São Vicente e Grenadines, Venezuela, Samoa. 
Tabela 1

Resultados dos testes de estacionariedade em painel

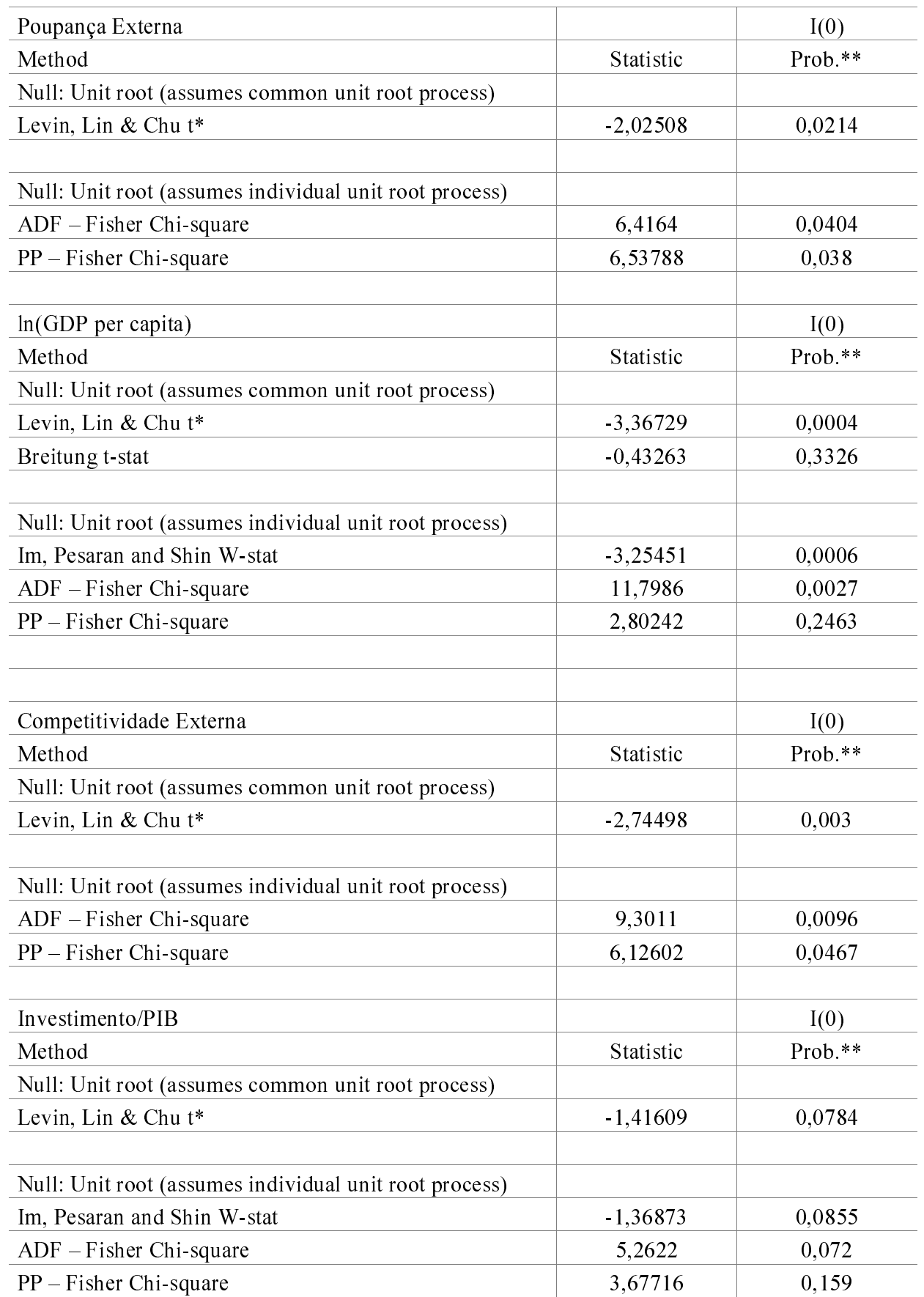

* Probabilities for Fisher tests are computed using an asymptotic Chi-square distribution. All other tests assume asymptotic normality. 
Para os três testes em questão, a hipótese nula é a de que todas as séries têm uma raiz unitária, ou seja, $\rho_{i}=0 \forall i$. No teste de Levin, Li e Chun (2003) estendem o teste de Levin e Lin para permitir a heterogeneidade nos valores do coeficiente autorregressivo sob a hipótese alternativa, ou seja, $\rho_{i}=\rho<0 \forall i$. A hipótese alternativa então pode ser escrita como $\rho_{i}<0$ para $i=1,2, N_{1}$ e $\rho_{i}=0$ para $i=N_{1}+1, \ldots, N$. Assim, sob a hipótese alternativa, algumas séries podem ser caracterizadas por uma raiz unitária, enquanto algumas outras séries podem ser ditas estacionárias. A Tabela 1 reporta os testes de raiz unitária para as séries utilizadas: o resultado das estatísticas aponta para a estacionariedade das séries, na maioria das estatísticas, para um nível de $10 \%$. Os testes incluem tendência e intercepto.

\subsection{Modelo empírico}

A ideia é a construção de um modelo empírico de crescimento demandside, nos moldes de modelos de crescimento keynesianos/kaleckianos. Nesse sentido, tomam relevância para a explicação da performance de crescimento dos países variáveis de política macroeconômica, em especial o papel das decisões de investimento e, mais importante, a dinamicidade e competitividade do setor externo, crucial para os países emergentes.

Para criar um índice da competitividade do setor externo, é estimado um índice de desvalorização real do câmbio, que é o desvio dos seus valores contemporâneos aos de longo prazo, previsto pela PPP e corrigido o efeito Balassa-Samuelson. As propriedades de estímulo sobre o crescimento do produto advindas da desvalorização real do câmbio para os países emergentes são empiricamente consolidadas ${ }^{22}$. O índice de desvalorização real do câmbio é descrito em Rodrik (2008). O autor defende a utilização de um índice de desalinhamento do tipo Balassa-Samuelson. De acordo com o autor, tal medida, que tem a vantagem de ser comparável entre os países ao longo do tempo, é calculada em três passos. Primeiro, utilizam-se as taxas de câmbio nominais $(e)$ e os fatores de conversão da paridade de poder de compra (PPP) para calcular a taxa de câmbio real dos países $i$ no período $t$. A equação (21) mostra esse cálculo variáveis utilizadas em logaritmos.

$$
\ln \theta_{i t}=\ln \left(e_{i t} / P P P_{i t}\right)
$$

Quando a taxa de câmbio real é maior que um, indica que o valor da moeda é menor do que o indicado pela paridade do poder de compra. Entretanto, como na prática os bens não comercializáveis são mais baratos nos países mais

(22) Os veículos teóricos da propagação dos efeitos da desvalorização sobre o crescimento são descritos em detalhe em Gala (2008) e, numa versão mais convencional, em Rodrik (2008).

Economia e Sociedade, Campinas, v. 20, n. 1 (41), p. 33-52, abr. 2011. 
pobres (de acordo com o efeito Balassa-Samuelson), é requerido um ajuste. Dessa forma, no segundo passo, é regredida a taxa de câmbio real sobre o PIB per capita (Ypcta), conforme mostra a equação (22) - sendo $f_{t}$ o efeito fixo para o período de tempo e $u_{i t}$ o termo erro.

$$
\ln \theta_{i t}=\alpha+\beta \ln Y \operatorname{pcta}_{i t}+f_{t}+u_{i t}
$$

Finalmente, o último passo é o cálculo do índice de depreciação real do câmbio que é medido de acordo com (23): a diferença entre a taxa de câmbio real contemporânea $\theta_{i t}$ e a taxa de câmbio prevista pelo modelo (os valores previstos da variável dependente):

$$
\ln (\text { Depreciação Re } a l)_{i t}=\ln \theta_{i t}-\ln \hat{\theta}_{i t}
$$

Assim, a depreciação real é comparável entre países e no tempo. Quando esse índice excede a unidade, indica que a taxa de câmbio é tal que os bens produzidos domesticamente são mais baratos, em termos de dólares - a moeda é relativamente depreciada. Por isso, o índice é utilizado no modelo empírico aqui estimado como uma proxy da competitividade externa da economia. A regressão com um painel de efeitos fixos da equação de câmbio real de longo prazo é reportada na Tabela 2 . Obtém-se um coeficiente estimado $\beta=-0,133$, o que sugere um forte efeito Balassa-Samuelson: quando a renda aumenta em 10\%, a taxa de câmbio aprecia em torno de 1,3\%.

Tabela 2

Estimação da taxa de câmbio real corrigida pelo efeito Balassa-Samuelson

\begin{tabular}{l|c|c|c|l}
\hline \multicolumn{2}{l|}{ Fixed-effects (within) regression } & \multicolumn{2}{l}{ Número de observações $=1.195$} \\
\hline \multicolumn{3}{l|}{ Group variable (i): countries } & Número de grupos $=73$ \\
\hline Ln $\theta$ & Coeficiente & Erro Padrão & $\mathrm{t}$ & $\mathrm{P}>\mathrm{t}$ \\
\hline LnYpcta & $-0,1333$ & 0,0503 & $-2,6500$ & 0,0080 \\
\hline Constante & 1,9592 & 0,4195 & 4,6700 & 0,0000 \\
\hline
\end{tabular}

Fonte: Resultados da pesquisa.

A equação empírica de crescimento estimada é a seguinte:

$$
\ln (Y / P)_{i t}=\alpha+\ln (Y / P)_{i t-1}+\beta_{1} \ln (I / Y)_{i t}+\beta_{2} \ln (P E X)_{i t}+\beta_{3}(C E X)_{i t}+\psi+\xi_{i t}
$$

Onde:

$\ln (Y / P)_{i t}$ é o logaritmo do PIB real per capita com índice Laspeyres fixo em 1996, série da World Penn Tables 6.2;

$\ln (Y / P)_{i t-1}$ é o logaritmo do PIB real defasado em um período (ano), série defasada da World Penn Tables 6.2; 
$\ln (I / Y)_{i t}$ é a proporção investimento/PIB, séria da World Penn Tables 6.2;

$\ln (P E X)_{i t}$ é a proxy da poupança externa definida como o quociente negativo das séries Conta Corrente a preços constantes e o PIB nominal a preços constantes, do World Development Indicators on-line;

$\ln (C E X)_{i t}$ é o índice de competitividade externa, gerada com as séries XRAT e $\ln (\mathrm{RGDPCH})$ da World Penn Tables 6.2, cuja construção é detalhada a seguir.

$\psi$ é um vetor com dummies de ano, uma para cada período de cinco anos da amostra;

$\xi_{i t}$ é um termo erro estocástico.

Para estimar a função é utilizado o estimador de métodos generalizados de momentos (Generalized Method of Moments, GMM) para painel dinâmico. Esses estimadores lidam com efeitos temporais não observáveis por meio da inclusão de interceptos específicos ao período. Tratar desses efeitos não é simples. Por isso, o modelo é dinâmico e pode conter regressores endógenos, que são controlados pela instrumentação das suas diferenças e defasagens.

Os instrumentos correspondentes às condições de momentos são valores defasados tanto em nível como em diferença das variáveis explicativas e dependentes. Uma vez que, tipicamente, as condições de momento sobreidentificam a regressão do modelo, o método do painel dinâmico permite teste de especificações através do teste de Sargan. Trabalhando sobre os estimadores de Arellano e Bover (1995), Blundell e Bond (1998) desenvolveram um estimador em sistema (system-GMM) que usa condições de momentos adicionais. Os estimadores de Arellano-Bond (1991) e Blundell-Bover foram considerados adequados para a análise deste trabalho, por permitirem uma especificação dinâmica (permitindo a variável dependente defasada), e por instrumentalizarem adequadamente variáveis potencialmente endógenas. Para uma descrição detalhada dessas metodologias econométricas, ver Baltagi (2005).

A Tabela 3 apresenta os resultados do modelo empírico de crescimento. Da especificação (I) à (IV) são estimadas várias formulações como forma de testar a potencial fragilidade dos coeficientes. $\mathrm{O}$ resultado geral mostra robustez dos resultados estimados. Os testes de Hansen e Hansen-in-Difference são recusados. O teste Arellano-Bond aponta autocorrelação de primeira ordem nos resíduos, rejeitando a hipótese nula para os resíduos na segunda ordem. A especificação (I) inclui, além da variável de PIB per capita defasada usual do modelo de painel autorregressivo, a variável poupança externa; as demais variáveis explicativas são adicionadas nas outras especificações, até (IV). Os coeficientes mostram resultados constantes e robustos ao teste de fragilidade nas especificações (I)-(IV). 
Tabela 3

Crescimento e Poupança Externa

\begin{tabular}{l|c|c|c|c}
\hline \multirow{2}{*}{$\ln (\mathrm{l}$ (PIBstem-GMM estimates } & $(\mathrm{I})$ & $(\mathrm{II})$ & $(\mathrm{III})$ & $(\mathrm{IV})$ \\
\hline \multirow{2}{*}{ Poupança Externa } & 1,006 & 1,003 & 0,996 & 0,987 \\
\cline { 2 - 5 } & $(0,002)$ & $(0,002)$ & $(0,005)$ & $(0,010)$ \\
\hline \multirow{2}{*}{$\ln ($ Competitividade Externa) } & $-0,614$ & $-0,778$ & $-0,663$ & $-0,775$ \\
\cline { 2 - 5 } & $(0,114)$ & $(0,205)$ & $(0,232)$ & $(0,345)$ \\
\hline \multirow{2}{*}{$\ln ($ Investimento/PIB) } & $\ldots$ & 0,010 & 0,011 & 0,012 \\
\hline \multirow{2}{*}{ Dummies de Ano } & $\ldots$ & $(0,001)$ & $(0,003)$ & $(0,005)$ \\
\hline \multirow{2}{*}{ Constante } & $\ldots$ & $\ldots$ & 0,021 & 0,023 \\
\hline AR(1) Teste & $\ldots$ & $\ldots$ & $(0,004)$ & $(0,006)$ \\
\hline AR(2) Teste & $-0,032$ & $-0,009$ & $-0,004$ & Sim \\
\hline Hansen J Test & $(0,016)$ & $(0,016)$ & $(0,044)$ & 0,074 \\
\hline Difference-in-Hansen Test & 0,000 & 0,000 & 0,000 & $0,082)$ \\
\hline Número de observações & 0,143 & 0,125 & 0,168 & 0,158 \\
\hline Número de países & 0,99 & 0,99 & 0,99 & 0,99 \\
\hline
\end{tabular}

* Entre parênteses, o desvio padrão das variáveis.

Obs.: (1) na especificação (I), Conta Corrente/GFP é variável endógena, instrumentalizadas por suas defasadas e diferenciadas; (2) na especificação (II), Conta Corrente e o Índice de Competitividade das Exportações são variáveis tratadas como endógenas, instrumentalizadas por suas defasadas e diferenciadas; (3) nas especificações (III) e (IV), a Conta Corrente/GDP, Índice de Competitividade das Exportações e o ln(Investimento/GDP) são tratadas como endógenas instrumentalizadas por suas defasadas e diferenciadas.

Os coeficientes positivos e significantes para a variável dependente defasada, em todas as especificações, indicam a persistência da correlação do produto per capita. Os valores positivos e significantes da variável de conta corrente/PIB indicam a relação positiva entre superávits dessa variável e a performance de crescimento dos países emergentes. Os índices de competitividade das exportações mostram relação positiva e significante com o desempenho macroeconômico dos países da amostra, sugerindo que os efeitos de uma taxa de câmbio relativamente desvalorizada são fatores de importância para o crescimento desses países. A variável de investimento, crucial para os modelos de crescimento de cunho pós-keynesiano, aparece com valores positivos e significantes em todas as especificações.

A variável "Poupança Externa" é incluída como contrapartida da série de conta corrente como proporção do PIB. O modelo empírico atesta uma influência negativa da poupança externa para o crescimento dos países selecionados na amostra, em todas as especificações. As razões pelas quais essa correlação é 
estatisticamente significante foram derivadas no modelo: a poupança externa, ao acumular um endividamento externo além de certo limite, tem um impacto negativo sobre o nível de atividade econômica. A dinâmica dessa relação é explicitada, por exemplo, por exemplo, nas palavras de Bresser e Nakano:

Depois de alguns anos de enorme acumulação de dívidas externa e interna, a situação financeira se deteriora. Tal deterioração cria expectativas de negativas sobre parte das empresas locais e internacionais (...) e a taxa de investimento diminui, levando à recessão. A conseqüente redução das receitas governamentais aumenta perversamente o déficit orçamentário. Por outro lado, os credores ficam cada vez mais inquietos. O risco-país aumenta, na medida em que a relação dívida externa/exportações cresce muito acima do limite de endividamento. Há tentativas de ataques especulativos. A reversão dos fluxos de capital pode começar por contágio, comportamento de manada e profecia que se cumpre por si mesma. O país está então sujeito ao default internacional e à crise interna (2003, p. 21).

\section{Conclusão}

Ao longo do presente artigo foi desenvolvido um modelo dinâmico não linear de inspiração pós-keynesiana para avaliar o impacto dos fluxos de poupança externa sobre a performance macroeconômica dos países em desenvolvimento. Daqui se segue que o influxo de capital externo, na medida em que tende a levar a um "endividamento externo excessivo", tem como resultado possível um equilíbrio de baixa lucratividade e uma baixa taxa de retorno sobre o capital, configurando assim uma situação de estagnação econômica. Isso porque no modelo aqui proposto, um equilíbrio no qual a taxa de lucro é baixa configura uma situação na qual o grau de utilização da capacidade produtiva também é baixo, uma vez que a participação dos lucros na renda é suposta como constante em função da constância da taxa de mark-up. Como a taxa de acumulação de capital é uma função positiva do grau de utilização da capacidade produtiva e negativa após o limite crítico de endividamento $\mathrm{z}^{*}$ - do endividamento externo como proporção do estoque de capital, segue-se que, no equilíbrio com alto endividamento, a taxa de crescimento do estoque de capital será menor do que a que prevaleceria caso a economia operasse com um nível mais baixo de endividamento. Um teste empírico de crescimento demand-side com painel dinâmico para 73 países confirma os potenciais efeitos negativos da poupança externa sobre o crescimento de longo prazo da amostra selecionada.

\section{Referências bibliográficas}

ARELLANO, A.; BOND, B. Some test specification for panel data: Monte Carlo evidence and an application to employment equations. Review of Economic Studies, 1991.

BALTAGI, B. Econometric analysis of panel data. John Wiley \& Sons, 2005. 
BLUNDEL, R.; BOND, S. Estimation in dynamic panel data models: improving on the performance of the standard GMM estimators. The Institute for Fiscal Studies, 2000.

BRESSER, L. C.; NAKANO, Y. Uma estratégia de desenvolvimento com estabilidade. Revista de Economia Política, v. 22, n. 3, 2002.

. Crescimento econômico com poupança externa? Revista de Economia Política, v. 23, n. 2, 2003.

GALA, P. Real exchange rate levels and economic development: theoretical analysis and econometric evidence. Cambridge Journal of Economics, v. 32, p. 273-288, 2008.

HESTON, A.; SUMMERS, R.; ATINA, B. Penn World Table Version 6.2. Center for International Comparisons of Production, Income and Prices at the University of Pennsylvania, 2006.

HOLLAND, M.; VIEIRA, F. Country risk endogeneity, capital flows and capital controls in Brasil. Revista de Economia Política, v. 23, n. 1, 2003.

KALDOR, N. A model of economic growth. Economic Journal, v. 67, 1957. . The role of effective demand in the short and long-run growth. In: BARRÉRE, A. (Ed.). The foundations of Keynesian analysis. London: Macmillan Press, 1988.

KEYNES, J. M. The Collected Writings of John Maynard Keynes. Editado por D. E. Moggridge. London: Macmillan, 1973. [No texto é referenciado por CWJMK].

LIMA, G. T. Progresso tecnológico endógeno, crescimento econômico e distribuição de renda. In: MACROECONOMIA moderna: Keynes e a economia contemporânea. Rio de Janeiro: Campus, 1999.

MARGLIN, S. Growth, distribution and prices. New York: Harvard University Press, 1984.

McCOMBIE, J. S. L.; THIRWALL, A. P. Economic growth and balance of payments constraint. New York: St Martin's Press, 1994.

MORENO-BRID, J. C. On capital flows and the balance of payments constraint revisited. Journal of Post Keynesian Economics, v. 21, p. 283-289, 1998-1999.

OREIRO, J. L. Prêmio de risco endógeno, metas de inflação e câmbio flexível. Revista de Economia Política, v. 22, n. 3, 2002.

- Poupança externa e performance macroeconômica. Revista de Economia Política, v. 24, n. 2, 2004.

POSSAS, M. L. Dinâmica da economia capitalista. São Paulo: Brasiliense, 1987.

RODRIK, D. Real exchange rate and economic growth: theory and evidence. John F. Kennedy School of Government, Harvard University, Draft, Jul. 2007.

SIMONSEN, M. H.; CYSNE, R. P. Macroeconomia. São Paulo: Atlas, 1995.

TAKAYAMA, A. Analytical methods in economics. Michigan: The University of Michigan Press, 1993.

TAYLOR, L. Macroeconomía estruturalista. Cidade do México: Trillas, 1989.

THIRWALL, A. The nature of economic growth. Aldershot: Edward Elgar, 2002. 